\title{
Effects of atmospheric variables on the performances of parabolic trough concentrating collector
}

\author{
Sadik Umar ${ }^{1}$, Umar Kangiwa Muhammad ${ }^{1}$, Muhammad Mahmoud Garba ${ }^{2}$, Hassan N. Yahya ${ }^{2}$ \\ ${ }^{1}$ Department of Physics, Kebbi State University of Science and Technology Aliero, Aliero, Nigeria \\ ${ }^{2}$ Sokoto Energy Research Center, Usmanu Danfodiyo University Sokoto
}

Email address:

umarmagajisadik@yahoo.com (S. Umar)

\section{To cite this article:}

Sadik Umar, Umar Kangiwa. Muhammad, Muhammad Mahamoud Garba, Hassan N. Yahya. Effects of Atmospheric Variables on the Performances of Parabolic Trough Concentrating Collector. American Journal of Energy Engineering. Vol. 2, No. 1, 2014, pp. $23-26$. doi: 10.11648/j.ajee.20140201.13

\begin{abstract}
In recent years solar energy has been strongly promoted as a viable energy source. one of the most simplest and direct application of this energy is the conversion of solar radiation in to heat energy using a devices called sollar collectors [3].In order to enhance this conversion efficiency, important parameters that influence the system performances need to be evaluated. To achieve the state objectives, this paper investigates the effects of some meteorological variables (Wind Speed and Ambient Temperature) on the performance of parabolic trough collector. The results obtained show that wind speed is inversely proportional to the direct solar radiation and it has also shown that a maximum daily average wind speed of $1.39 \mathrm{~m} / \mathrm{s}$ was observed, when ambient temperature reach it lowest value. Furthermore, efficiency is highly correlated with wind speed and negatively correlated with ambient temperature.
\end{abstract}

Keywords: Parabolic Trough Collector, Direct Solar Radiation, Efficiency, Wind speed, Ambient Temperature, Concentrating Collector

\section{Introduction}

Energy is one of the most important factors in social and economic development of a country. The amount of energy consumption per capita of a country is the measure of the nation's economic development and it has become an important parameter for sustainable development through the world [7].Energy demands across the world have been on a rapid rise recently due to population growth and industrialization. It is obvious that the conventional energy sources (Fossil Fuels) are under increasing demand and there is a need to examine alternative sources to augment these energy sources [8]. The sun represents one such alternative energy sources, which is presently underutilized particularly in sub Saharan Africa, where there is abundant sun radiation. Solar energy is a renewable and sustainable energy source. It has a promising potential to meet our present and future energy needs. In their course to develop solar thermal technology as an alternative and most prospective, sustainable source of energy for steam production for both industrial and domestic application. "Reference[4], in his effort to generate steam using solar energy ,parabolic dish collector was constructed using wood, aluminum sheet and plane mirror and a temperature $200^{\circ} \mathrm{C}$ was obtained".

"Reference [5] investigates the effect of reflective materials on the performance of parabolic trough concentrator by using three different reflective materials, Aluminum sheet, car solar reflector and Aluminum foil reflector, where it was found that Aluminum sheet reflector has the highest performance followed by car solar reflector and then Aluminum foil". There also, to enhance the performance of solar parabolic trough concentrator, numerous research groups and individual around the world have contributed to the performance improvement of the solar parabolic trough concentrating collector, by evaluating the influence of some important parameters on the performance of the system. The present work investigates the effect of some atmospheric parameters (Ambient temperature and Wind speed) on the thermal performance of parabolic trough solar collector. 


\section{System}

\subsection{System Description}

Figure 1 shows the schematic diagram of a solar parabolic trough concentrator. The overall dimensions are shown in table 1 . The system comprised of a parabolic trough shape and receiver tube. The parabolic trough shape was made up of ply wood and soft wood joined together and a mirror of $3 \mathrm{~mm}$ thickness was cut in to rectangular shape of $8 \mathrm{~cm} \times 94 \mathrm{~cm}$. The rectangular shaped mirror was fixed with shinny side facing up on to parabolic trough shape made from wood, which in turns formed a parabolic reflective surface. The parabolic trough takes the advantage of all the parallel rays from the sun that incident on it and converge it at the focal point [2]. The black painted copper tube of $28.5 \mathrm{~mm}$ thickness was placed at a focal point to serve as receiver tube (absorber).

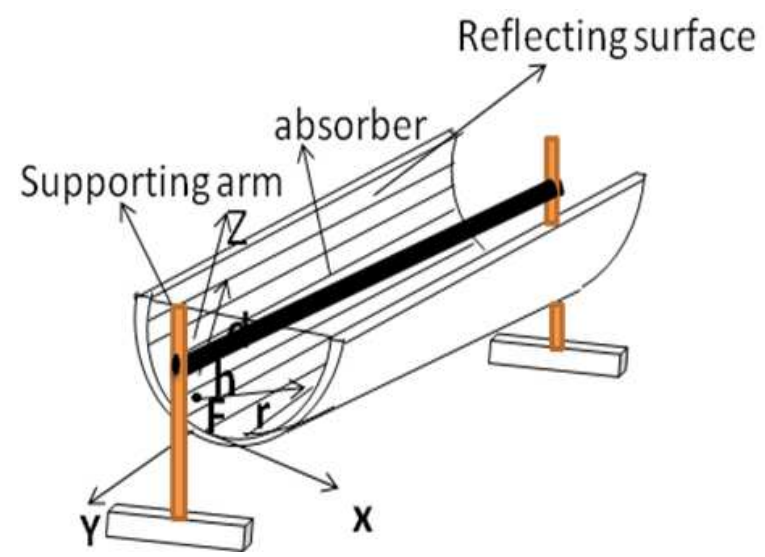

Figure 1. Schematic diagram of a solar parabolic trough concentrator

\subsection{Parabolic Trough Collector Working Principle}

Figure 2 Shows a typical parabolic trough collector (PTC), which is basically comprised of a parabolic trough shaped concentrator that are capable of reflecting direct solar radiation on to a receiver tube located in the focal line of parabola [8]. Since the collector aperture area is bigger than the outer surface of the receiver tube, the direct solar radiation (beam radiation) is concentrated.

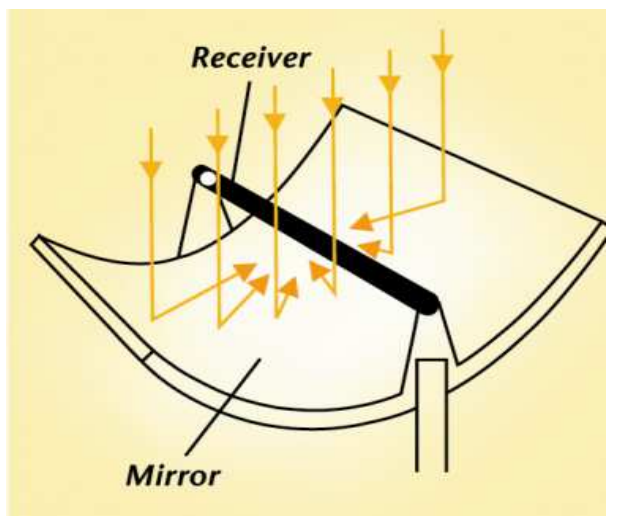

Figure 2. A typical parabolic trough concentrator [1]
The concentrated radiation reaching the reciever tube heats the fluid that circulates through it, thus transforming the solar radiation in to thermal energy in the form of sensible of the fluid [9]

Table 1. Parabolic trough collector system specifications

\begin{tabular}{ll}
\hline Parameters & Values \\
\hline Focal distance F & $0.15 \mathrm{~m}$ \\
Depth of the parabolic trough & $0.33 \mathrm{~m}$ \\
Length of collector & $1.82 \mathrm{~m}$ \\
Absorber Area & $2.85 \mathrm{~cm}^{2}$ \\
Aperture Area & $1.64 \mathrm{~m}^{2}$ \\
\hline
\end{tabular}

\section{Experimental Setup}

The Parabolic trough Concentrator was set for performance evaluation test at Sokoto energy research Center testing area, under climatic conditions of Dundaye Village, Sokoto state, Nigeria (Latitude $13.1^{\circ}$ North and Longitude $5.2^{\circ}$ ). The water tank was elevated at $0.5 \mathrm{~m}$ above the ground level in such a way that water can flow downstream to the receiver tube. The test was done at constant flow rate $\left(\mathrm{m}_{\mathrm{w}}\right)$ of $0.0177 \mathrm{~kg} / \mathrm{min}$. The parameters recorded during the test were: water inlet temperature $\left(\mathrm{T}_{\mathrm{i}}\right)$, outlet temperature $\left(\mathrm{T}_{\mathrm{f}}\right)$, intensity of diffused solar radiation $\left(\mathrm{I}_{\mathrm{d}}\right)$, global $\left(\mathrm{I}_{\mathrm{g}}\right)$ and direct $\left(\mathrm{I}_{\mathrm{b}}\right)$, ambient Temperature $\left(\mathrm{T}_{\mathrm{amb}}\right)$, and wind speed at parallel to the system using digital Anemometer. The thermocouple data logger was also used for temperatures measurement of four different points, ambient, absorber, inlet temperature of water and out let temperature of water simultaneously. The ambient temperature was measured by placing the thermocouple terminal at the surrounding. The absorber temperature was also read and recorded by using a temperature resistive material to gum the thermocouple terminal on the absorber surface, the inlet and outlet water temperature was measured and recorded for Seven hours (from 9:00am to 4:00) at 30 minutes interval.

The parabolic trough collector utilizes only direct component of solar radiation, therefore in order to measure direct solar radiation, two pyranometers were used one to measure global and another one measured diffuse and then direct was obtained by subtracting diffuse from global.

Therefore Collector Field efficiency was computed using equation (1) as [6].

$$
\eta_{c}=\frac{\left(T_{f}-T_{i}\right) m_{w} C_{p}}{A I_{b}}
$$

Where $\mathrm{A}=$ Area of the collector $\left(\mathrm{m}^{2}\right)$ $\mathrm{C}_{\mathrm{p}=}$ the specific heat capacity of fluid $\left(\mathrm{KJ} / \mathrm{Kg} /{ }^{\circ} \mathrm{C}\right)$

$\mathrm{M}_{\mathrm{w}}=$ Collector field flow rate $(\mathrm{Kg} / \mathrm{s})$

$\mathrm{T}_{\mathrm{f}}, \mathrm{T}_{\mathrm{i}}=$ Collector field temperatures at outlet and inlet $\left({ }^{\circ} \mathrm{C}\right)$

$\mathrm{I}_{\mathrm{b}}=$ direct solar radiation $\left(\mathrm{W} / \mathrm{m}^{2}\right)$

$\eta_{\text {field }}=$ Collector field efficiency

The flow rate was converted from $\mathrm{Kg} / \mathrm{min}$ to $\mathrm{Kg} / \mathrm{s}$. 


\section{Results and Discussion}

The significant of carrying out this experimental work was to find the effect of some weather parameters on the performance of parabolic trough collector. In order to achieve this target, the experimental test was carried out for six consecutive days (from 20.10.11 to 25.10.11) for seven hours daily at 30 minutes interval and the average was taken for each day. The daily average data was used in equation (1) to calculate the collector field efficiency for each day and the results is shown in figure 3-5:

Figure 3 represents the average daily variation of ambient temperature, wind Speed and efficiency for six days at 30 minute interval. According to results in figure 3 the higher average daily wind speed of $1.39 \mathrm{~m} / \mathrm{s}$ was obtained on the sixth day, when ambient temperature is $42.8^{\circ} \mathrm{C}$ and efficiency $5.59 \%$ was attained. The lowest wind speed of $0.65 \mathrm{~m} / \mathrm{s}$ was observed on the second day at $40.5^{\circ} \mathrm{C}$ Ambient temperature and efficiency of $7.0 \%$ was observed, efficiency had it peak value of $8.36 \%$ on the third day when Ambient temperature has its lowest value of $37.2^{\circ} \mathrm{C}$ and wind speed of $1.30 \mathrm{~m} / \mathrm{s}$ was recorded. The highest efficiency was obtained when the ambient temperature has the least value. This shows that ambient temperature is inversely proportional to the efficiency. Although both the wind speed and ambient temperature fluctuates due to changes in the day but in most of the time an increased in wind speed decreases ambient temperature.

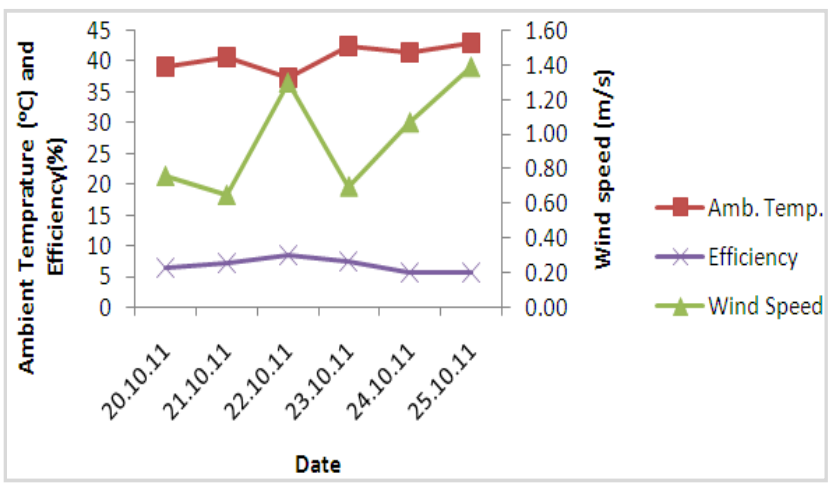

Figure 3. Average daily variation of ambient temperature, Wind Speed and Efficiency.

Figure 4 is a graph of daily average wind speed, ambient temperature and direct radiation. The result shows that ambient temperature increases with an increase in direct solar radiation and also decreases with the decrease in radiation, while wind speed increase with the decrease in ambient temperature. This indicates that higher wind speed is observed in the morning or evening period when solar radiation and ambient temperatures are low. Therefore, it has been clearly justified that there exists relationship between direct solar radiation, ambient temperature and wind speed.

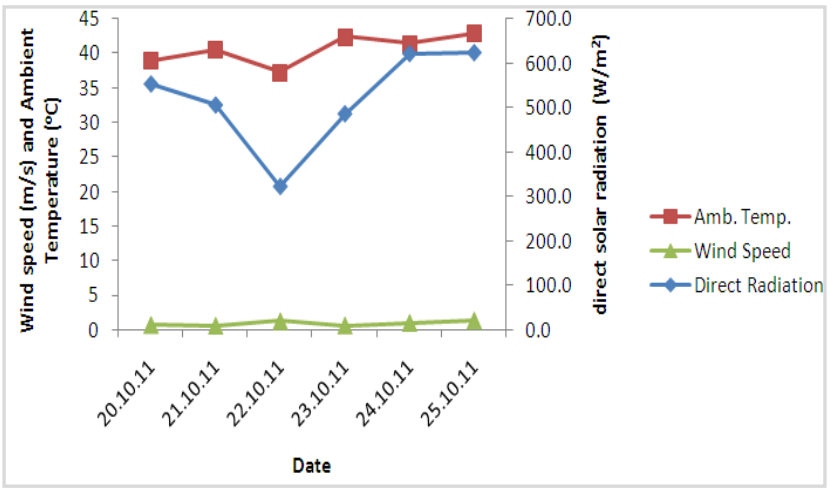

Figure 4. Average daily variation of Ambient temperature, Wind Speed and direct radiation.

Figure 5 Shows variations of daily average direct solar radiation, ambient temperature, wind speed and efficiency. In this figure direct solar radiation and ambient temperature are highly correlated, while at the same time efficiency and wind speed are correlated, therefore wind speed shows a negative effect on direct solar radiation and also ambient temperature shows a negative effects on efficiency but positive effect on solar radiation, wind speed also shows a positive effect on efficiency.

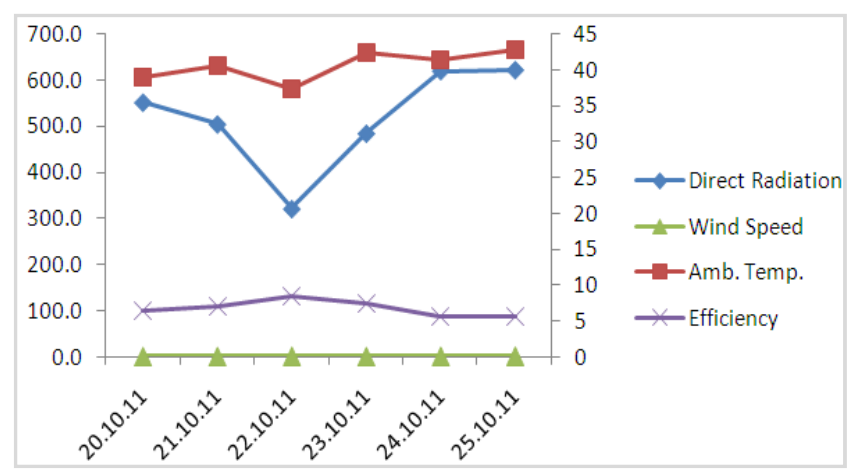

Figure 5. Daily Average Variation of Ambient temperature, direct solar radiation, wind speed and Efficiency.

\section{Conclusion}

Parabolic Trough Collector was tested under the climatic condition of Aliero Town, Kebbi State, Nigeria to see the effect of meteorological parameters on the performance of the system. From the experimental results obtained it has shown that lowest daily average ambient temperature of $37.2^{\circ} \mathrm{C}$ was recorded at $1.30 \mathrm{~m} / \mathrm{s}$ daily average wind speed while efficiency has its peak value of $8.36 \%$. It is therefore, indicates that efficiency and wind speed has positive correlation and negatively correlated with ambient temperature. Furthermore, wind speed is negatively correlated with direct solar radiation. However it clearly indicates that ambient temperature and wind speed affects the thermal performance of the parabolic trough collector. 


\section{References}

[1] J. Dascomb. (2009), "Low cost concentrating solar collector for steam generation". Unpublished Thesis Submitted for the ward of Doctor of Philosophy, Department of Mechanical Engineering, Florida State University. Retrieved on $6^{\text {th }}$ may, 2011. From http://esc.fsc.edu/documents/Dascomb JThesis.pdf

[2] J.F.M.Escobar, S. Vazquez, Y. Montiel, F. GranadosAgustin, Cruz-Martinez \& E. Rodriquez-Rivere,(2011) "Building a parabolic solar concentrator prototype". Journal of Physics, Conference series 274 (2011). Retrieved on $5^{\text {th }}$ August, 2011. From iopscience.iop.org/17426596/274/012104. Pdf.

[3] G. Iordanou, (2009) "Flat Plate Solar Collectors for Water Heating with Improved Heat Transfer for Application in Climatic Conditions of the Mediterranean Region”. PhD Thesis, Durham University. Available at durham E-theses online: http://etheses.dur.ac.uk/174/.Retrieved $0 \mathrm{n}$ $17^{\text {th }}$ December,2010. (unpublished)

[4] F. Joshua, (2009). "Design, construction and testing of parabolic solar steam generator". Leonardo Electronic Journal of practices and Technologies. Retrieved on $16^{\text {th }}$ December, 2010 from http://lejptacademicdirect.org/A14/115_133.pdf

[5] M. Kawira, R. Kinyua, \& J.N. Kamau, (2010) “.Fabrication and characterization of a prototype parabolic trough solar concentrators for steam production", Retrieved on $18^{\text {th }}$ june, 2011.From http://elearning.jkuat.ac.ke/journals/ojs/index.php/sr.

[6] A. Thomas, (1991). "Operation and performance of the solar steam generation system installed at government silk factory, mysore". Energy conversion management, Vol. 33 (3), Pp191-196.

[7] Varun and S. K Singal, (2007), "Review of augmentation of energy needs using Renewable energy resources in india". Renewable and Sustainable Energy, 11:1607-15.

[8] E.Zarza,(2005), "Medium Temperature Solar Concentrators". Solar energy Conversion and Photo energy system. Vol.1. Encyclopedia of support system (EOLSS).

[9] E. Zarza, L. Valenzuela, J. Leon, K. Hennecke, M.Eck, D.H.Weyers, M. Eickhoff (2002), "Direct steam generation in parabolic troughs". Final result and conclusions of the DISS project. In. Steinfeld, A (eds) Book of proceedings of $11^{\text {th }}$ Solarpaces international symposium on concentrated solar power and Chemical energy Technologies, held in Zurich (Suitzerland) September $4^{\text {th }}-6^{\text {th }}, 2002$. Paul Scherer institute, Villigen (Suiza), 2002, Pp 21-27 ISBN 3-95214093-7 